\title{
The epidemiology of panic disorder and agoraphobia in Europe
}

\author{
R.D. Goodwin ${ }^{\text {a,* }}$, C. Faravelli ${ }^{\text {b }}$, S. Rosi ${ }^{\text {b }}$, F. Cosci ${ }^{\text {b }}$, E. Truglia ${ }^{\text {b }}$, R. de Graaf ${ }^{\text {c }}$, H.U. \\ Wittchen ${ }^{\text {d,e }}$
}

a Department of Epidemiology, Mailman School of Public Health, Columbia University, New York, 722 West 168th Street, USA

b Department of Neurology and Psychiatry, University of Florence, Florence, Italy

c Trimbos-Instituut, Netherlands Institute of Mental Health and Addiction, Utrecht, The Netherlands

d Max-Planck-Institute of Psychiatry, Unit Clinical Psychology and Epidemiology, Munich, Germany

e Institute of Clinical Psychology and Psychotherapy, Technische Universität Dresden, Germany

\begin{abstract}
A literature search, in addition to expert survey, was performed to estimate the size and burden of panic disorder in the European Union (EU). Epidemiologic data from EU countries were critically reviewed to determine the consistency of prevalence estimates across studies and to identify the most pressing questions for future research. A comprehensive literature search focusing on epidemiological studies in community and clinical settings in European countries since 1980 was conducted (Medline, Web of Science, Psychinfo). Only studies using established diagnostic instruments on the basis of DSM-III-R or DSM-IV, or ICD-10 were considered. Thirteen studies from a total of 14 countries were identified. Epidemiological findings are relatively consistent across the EU. The 12-month prevalence of panic disorder and agoraphobia without history of panic were estimated to be $1.8 \%(0.7-2.2)$ and $1.3 \%(0.7-2.0)$ respectively across studies. Rates are twice as high in females and age of first onset for both disorders is in adolescence or early adulthood. In addition to comorbidity with agoraphobia, panic disorder is strongly associated with other anxiety disorders, and a wide range of somatoform, affective and substance use disorders. Even subclinical forms of panic disorder (i.e., panic attacks) are associated with substantial distress, psychiatric comorbidity and functional impairment. In general health primary care settings, there appears to be substantial underdiagnosis and undertreatment of panic disorder. Moreover, panic disorder and agoraphobia are poorly recognized and rarely treated in mental health settings, despite high health care utilization rates and substantial long-term disability.
\end{abstract}

Keywords: Panic disorder; Epidemiology; Panic attacks; Agoraphobia; Burden

\section{Introduction}

Panic disorder is a severe and persistent mental disorder, associated with a high degree of subjective distress, occupational and social disability (Wittchen, 1988; Klerman et al., 1991). A panic attack (PA) is the core syndrome (not a codable diagnosis) of panic disorder and is defined as a discrete period of intense fear or discomfort accompanied by somatic and psychic symptoms, which may or may not be precipitated by exposure to a phobic stimulus (American Psychiatric Association, 1994, ICD-10, World Health Organization, 1993). Panic attacks typically include acute, somatic symptoms, which can involve cardiovascular, respiratory, neurological-like, and gastrointestinal symptoms, sweating, chills and/or hot flushes and psychological symptoms (i.e., dizziness, unsteadiness, light-headedness, fear of losing control/dying/going crazy). Panic attacks are characterized by sudden onset, rapidly building to a peak usually within 10-30 min, and are accompanied by a sense of imminent danger or impending doom and an urge to escape. 
According to DSM IV (APA, 1994), PD is diagnosed when an individual presents both recurrent unexpected panic attacks and at least one of the following: (a) persistent concern of having additional attacks, (b) worry about the implications of the attacks and consequences (heart attack, dying, losing control) and (c) a significant change in behaviour as a consequence of the attack. In addition, the diagnosis of PD requires a complex set of differential diagnostic considerations, because the core feature, panic attacks, can also occur in many other conditions and situations, such as a direct physiological consequence of substance use (i.e., caffeine intoxication) or medical conditions (hyperthyroidism) or in the context of other mental disorders (PTSD, social phobia). PD is frequently occurring with agoraphobia (PD with agoraphobia), defined as anxiety about being in places or situations from which escape might be difficult or embarrassing or in which help might not be available in the case that escape is needed. Agoraphobia is characterized by subjective distress and marked avoidance of such situations. AG frequently co-occurs jointly with PD, but may also occur independently (agoraphobia without PD) (APA, 1994). Panic disorder (PD) and associated syndromes and conditions, such as panic attacks (PA) and panic disorder with agoraphobia, have been examined in several epidemiological investigations as well as systematic international reanalyses of existing data sets.

Several studies examining data from prospective-longitudinal studies in the community have focused on panic disorder. Specifically, a number of studies have examined the strength of associations between panic disorder and risk for comorbid anxiety, mood, and substance use disorders. A number of studies have also examined the role of panic attacks as a core psychopathological phenomenon for many mental disorders in an effort to clarify meaningful thresholds for defining psychopathology (Reed and Wittchen, 1998; Goodwin and Hamilton, 2001; Goodwin et al., 2004).

\section{Aims}

The central aim of this paper is to review epidemiological surveys in the community that provide data on panic disorder with and without agoraphobia in Europe, focusing on identifying similarities and differences of the prevalence rates from various studies. Further, available information on age of onset, comorbidity with physical and mental disorders, and burden associated with panic disorder will be reviewed.

\section{Methods}

A literature search (Medline, Web of Science, Psychinfo) was performed using the following key words and related terms: epidemiology, prevalence, incidence, community, general population, mental disorders, psychiatric diagnoses/diseases, anxiety, panic attack, panic disorder, agoraphobia. The search was run for years 1990 to 2004 (English language or at least an abstract in English). The search was restricted to the last two decades because the majority of studies from the 1980s were launched in the late 1970s before explicit diagnostic criteria were used. Additionally, experts from several countries were contacted to supplement the search with results from studies not available via electronic search, and to include papers currently in press as well as unpublished data, if accessible. For further details, see Wittchen and Jacobi (2005).

\section{Results}

\subsection{2-Month prevalence of panic disorder and agoraphobia}


A total of 13 national or regional studies, as well as one cross-national study involving six EU countries, were identified and listed in Table 1 . None of the studies was designed specifically to study panic disorder. We did not find any epidemiological studies in primary care settings or in other mental and non-mental health specialist settings.

The methodological differences between studies need to be taken into account in interpreting these findings. Specifically, (a) some studies are based only on highly selective cohorts, for example, the Dresden study includes young females only, and the age cohort studies from Zurich and Munich refer to specific age groups or adolescence and young adulthood only; (b) most studies indicate 12-month prevalence estimates (except for the Dresden and the Great Britain study, for which only 1- week cross-sectional rates were reported); (c) seven studies used the Composite International Diagnostic Interview (CIDI, Wittchen, 1994), related instruments (DIS), or modifications thereof (M-CIDI, Wittchen et al., 1998d) to ascertain the diagnostic status. The remaining studies used either the SCAN or study-specific developments. The heterogeneity of diagnostic instruments indicates that the studies might have used different diagnostic algorithms; (d) the majority of prevalence estimates refer to samples with an age range of 18-65. Only one study covers subjects beyond this age.

Accounting for differences in sampling and design, Table 1 reveals a relatively consistent pattern of the 12-month prevalence across all studies.

\subsubsection{Panic disorder}

The majority of findings on the 12-month prevalence of PD cluster around $2 \%$ (median across studies 1.8\%). The two studies investigating 1-week prevalence (Becker et al., 2000; Jenkins et al., 1997) reported lower estimates. Lower estimates were also reported from an unpublished report from the Czech Republic (0.3\%) and the ESEMED study (0.8\%). Because no confidence intervals were available, however, we were unable to test for significance of differences between rates. It appears that studies including a higher proportion of older respondents (or fewer younger subjects) tended to have lower estimates. Consistently across studies, rates are higher among females (1.0-5.6\%) compared with males (0.6-1.5\%). Rates for panic attacks were reported in only three studies Rates of panic attacks were consistently higher among females (2.2\% males and 5.6\% for females) and at least 2-3 times higher as compared with those for full-blown panic disorder (Reed and Wittchen, 1998). The 12-month prevalence rates are fairly stable across the age groups and studies. Fig. 1 summarizes the findings of the two studies that have reported age-group-related pre-valences, the NEMESIS and the GHS-MHS study (Wittchen et al., 2000). Except for different rates of agoraphobia among females, the findings from the two studies are consistent.

\subsubsection{Agoraphobia}

Rates for agoraphobia are difficult to evaluate, because some studies report prevalence rates for agoraphobia in general, whereas others only indicate rates for agoraphobia without history of PD. As such, there seems to variability in findings. 12-Month total rates vary from 0.4 to $3.1 \%$; the median across all studies is $1.3 \%$ (range $0.7-2.0$ ), gender: male $0.6 \%$, female $1.5 \%$.

\subsection{Age of onset, incidence and natural course}

A small number of studies have provided detailed data about the age of first onset distribution for panic disorder and agoraphobia. Only three of the studies listed (EDSP, Wittchen et al., 
1998b; NEMESIS, Bijl et al., 1998; Zurich, Vollrath et al., 1990) involve a prospectivelongitudinal design to examine prospectively the incidence of panic attacks and panic disorder. Most available data on age of onset comes from crude retrospective data that report an onset sometimes more than three decades ago. The EDSP and the Zurich cohort studies show that PA and PD can begin early, often during childhood or early adolescence (Reed and Wittchen, 1998; Wittchen et al., 1998b; Vollrath et al., 1990). The retrospective mean age of onset reports for PD is typically in the early to middle 20s (Weissman et al., 1997), with ages of onset for agoraphobia slightly higher.

There is evidence of a wide variation and unequal distribution of the age of onset of PD for males and females. More detailed hazards analyses on the EDSP data set (Isensee et al., 2003) have suggested a unimodal distribution for females with evidence for a fairly steady increase in risk for panic attacks occurring after age 10 up to age 28. In contrast, among males, there is some evidence for a bimodal distribution. In line with similar findings from the US (Burke et al., 1991), there are data suggesting for males a second period of increased risk in the late 40s. There are unfortunately no publications describing in greater detail such patterns of incidence of panic attacks, PD, and agoraphobia. Studies with incidence data include the Lundby study (Grasbeck et al., 1993), the NEMESIS project (Bijl et al., 2002), the Dresden study (Becker et al., 2000) and the EDSP project (Wittchen et al., 1998b). Due to the extremely different design features (sample composition of various ages and sexes, and differences in the incidence observation period, varying from 1-2 years over 4 years to 30 years) between these studies, it is impossible to make meaningful comparisons between these studies.

Most studies conducted in clinical settings suggest that PD is generally a chronic condition, although with some waxing and waning of the symptomatology (Faravelli and Paionni, 2001). In long-term studies, between 17 and $70 \%$ of patients still have panic attacks, and between 36 and $82 \%$ have phobic avoidance at follow-up (Katschnig and Amering, 1998).

\subsection{Risk factors}

Beyond some broad sociodemographic correlates, few potential risk and vulnerability factors for PD, PA and agoraphobia with PD have been examined in any of the epidemiological surveys reviewed. For panic and agoraphobia, most studies reveal 2- to 3-fold higher rates for females as compared to males, although this gender difference seems to diminish - at least in some studies - in older age groups due to proportionally higher incidence rates of panic in males. Age has been suggested as a risk factor for PD in part due to the observation that rates of PD among adults over 60 are considerable lower than those of subjects in the first three decades of life. This difference, however, could be due to the fact that standardized diagnostic for mental disorders instruments might not be sensitive and valid in the elderly (Knäuper and Wittchen, 1994). There is also some speculation of an inverse relationship between PD and lower socio-economic status (Kohn et al., 1998), although there is no clear evidence that this variable can be regarded as a risk factor as opposed to a correlate of this condition. In European studies, no significant association between PD and education, employment status, or occupational prestige have been found (Meltzer et al., 1995; Wittchen et al., 1998d).

To our knowledge, there is currently little epidemiological evidence regarding other potentially conceptually important risk factors, which have shown to be relevant in clinical studies of PD. These include the role of family genetic factors (a family history of PD but possibly also of other anxiety and mood disorders), a prior history of childhood anxiety disorders including separation anxiety, phobias and overanxious disorder, temperament (especially behavioural inhibition), cognitive predispositions such as anxiety sensitivity (a 
tendency to catastrophically misinterpret and fear physiological sensations associated with arousal), somatic conditions (especially respiratory illness), early and recent trauma and negative life events and parenting styles such as overprotection and rejection (Faravelli and Paionni, 2001; Fredman et al., 2003; Zaubler and Katon, 2003).

\subsection{Association with other disorders}

PD is found to be highly comorbid with a wide range of other mental disorders. This pattern is fairly consistent across all available European community studies (Vollrath et al., 1990; Wittchen et al., 1998c; Faravelli et al., 2004; Jacobi et al., 2004; The ESEMeD/MHEDEA 2000 investigators, 2004b). Patterns seem to be identical to those established in international studies (Weissman et al., 1997; Roy-Byrne et al., 2000). Significant associations exist with almost all anxiety, mood, substance and somatoform disorders. In most of the studies, „pure“ PD (i.e., without any comorbid mental disorder) appears to be rare. Most frequent lifetime and cross-sectional comorbid patterns were those with depressive disorders, followed by other anxiety disorders. According to prospective-longitudinal findings, PD may precede or follow other disorders (Roy-Byrne et al., 2000). It is also noteworthy that most studies also report increased odds for bipolar disorders (Faravelli et al., 2004) as well as strong associations between PD and alcohol/ substance use disorders and somatoform disorders (Merikangas et al., 1996; Wittchen et al., 1998b; Faravelli et al., 2004). PD also seems associated with various physical disorders, including cardiovascular (Weissman et al., 1990; Mansour et al., 1998) and respiratory disease (Pollack et al., 1996; Goodwin et al., 2003), vestibular dysfunction (Jacob et al., 1996), headache (Marazziti et al., 1999) and irritable bowel syndrome (Kaplan et al., 1996).

Available data suggest similarly high comorbidity rates between agoraphobia and mood and other anxiety disorders (Wittchen et al., 1998c; The ESEMeD/MHEDEA 2000 investigators, 2004b). Rarely however have patterns of comorbidity of agoraphobia and comorbid mental disorders been studied with similar sophistication and detail as those for PD.

\subsection{Panic attacks}

Similar to other mental disorders, the current diagnostic criteria for PD have been subject to discussions of revisions. For example with regard to (a) definitions for subthreshold or sporadic panic attacks (Von Korff et al., 1985; Vollrath et al., 1990), (b) the inclusion of specific symptoms (Aronson, 1987) and particularly (c) the relationship between panic attacks and panic disorder and agoraphobia (Wittchen et al., 1998b). Some authors - especially those from the US - consider panic attacks to be the primary pathological phenomenon and central feature of the disorder, with agoraphobia as an avoidance behaviour only secondary to, or derived aetiopathogenetically and chronologically secondary to panic disorder (Klein, 1987). In fact, DSM-IV considers agoraphobia a residual diagnosis. Others - more consistent with traditional European perspectives as codified in the ICD-10 classification - contend that agoraphobia occurs with and without panic attacks (Reed and Wittchen, 1998; Wittchen et al., 1998b). Thus, it is believed that agoraphobia is a separate diagnosis that describe a behavioural syndrome reflected by conditioned avoidance to specific phobic situations, possibly associated with pathogenic experiences (Marks, 1987; Lelliott et al., 1989). Consistent with the latter perspective, epidemiologic studies have shown that panic attacks occur in a wide variety of conditions including somatic illness, depression, obsessivecompulsive disorder, alcohol abuse, borderline states, acute psychosis and in individuals without other mental disorders. As a consequence, panic attacks per se are regarded by some authors to be a sensitive marker of more severe psychopathology, which becomes 
diagnostically relevant when it occurs under specific conditions (e.g., family genetic disposition, pre-existing cognitive patterns, anxiety sensitivity, vulnerability to environmental events, coexisting phobic anxiety, temperamental traits) (Wittchen et al., 1998c; Reed and Wittchen, 1998; Goodwin and Hamilton, 2001; Goodwin et al., 2004).

\subsection{Treatment}

Although none of the studies provides a broader description of the health care utilization behaviour and the actual treatment rates of panic disorders and agoraphobia, there is some evidence that subjects with PD are more likely to seek professional help than subjects with other mental disorders. Regarding primary care, a study of five European centres showed that $60 \%$ of the subjects with PD without agoraphobia and nearly $90 \%$ of the subjects with PD and agoraphobia were recognized as „psychiatric cases“ by their GPs. Only a minority, however, were prescribed with anxiolytics or antidepressants (Weiller et al., 1998). In the Health Interview and Examination Survey (Jacobi et al., 2004), PD was the most frequently „treated“ disorder. Treatment, defined as having contacted a health care professional because of panic symptoms at least once, was reported by almost $60 \%$ of all subjects with PD. There is also evidence that treatment is more likely among cases with comorbidity, such as depression (Bijl et al., 2003). A community sample of adolescents and young adults (EDSP, Wittchen et al., 1998b; Wittchen, 2000) showed that despite high utilization rates, the proportion of patients receiving „appropriate“ treatment was extremely low (8\%). In this study, appropriate treatment was defined as either antidepressant treatment or cognitive-behavioural therapy. With the exception of one study, no data on treatment rates for agoraphobia without PD are available. This study suggested that patients with agoraphobia might be even less frequently recognized and treated than PD (Wittchen et al., 1998a).

\subsection{Impairment, disability and other adverse consequences}

High levels of disability and impairment and marked reductions in quality of life associated with PD are well documented (Faravelli et al., 1989; Vollrath et al., 1990; Wittchen et al., 1998b). PD ranks among the five mental disorders with the strongest impact in terms of work loss days and reduced quality of life. The impact of PD seems stronger than that associated with several common chronic physical disorders (The ESEMeD/MHEDEA 2000 investigators, 2004c). Among adults with PD, even poorer quality of life is predicted by comorbid depression, low social support, worry and severity of chest pain (Katerndahl and Realini, 1997). PD patients in comparison to controls are at higher risk of suicide as well as an increased general morbidity and mortality (Coryell, 1988; Weissman et al., 1989; Lepine et al., 1993). However, since PD is frequently comorbid with other psychiatric and somatic disorders, these long-term consequences could be attributed to these associated conditions and in fact some studies seem to confirm this position (Johnson et al., 1990; Lepine et al., 1993; Wunderlich et al., 1998).

\section{Discussion}

Across the 14 EU countries studies and 13 studies reviewed, the 12-month prevalence rates for panic disorder were found to be fairly consistent. 1.8\% of the adult population aged 18-65 was found to suffer from PD. The prevalence of agoraphobia without panic disorder was 1.3\%. Extrapolating these estimates in number of subjects affected and assuming a fairly even distribution across all European states, we can estimate that 4.3-5.3 million of the adult EU population suffer from PD, and about four million (3.3-4.7) from agoraphobia without panic. 
Panic disorder was consistently more common among females (3.0\%) compared to males (1.7\%); for agoraphobia, the gender difference appeared to be even larger (3:1). Across the age span 18-65 examined, the prevalence distribution by age group for both conditions appeared to be relatively similar. There was agreement from prospective- longitudinal as well as retrospective studies that PD may start young as early adolescence or even childhood. The majority of all panic cases in the community report an onset before age of 25 . Onset characteristics for agoraphobia have not been examined in similar detail. Available data suggest, however, that the onset might be slightly later in the late 20s. Only two studies have provided some evidence of different incidence patterns in males and females (Burke et al., 1991; Wittchen et al., 1998c). This finding should be considered preliminary and requires replication.

Even when controlling for comorbidity, there is also agreement across studies that panic disorder with and without agoraphobia is a severe and not infrequently disabling condition, associated with increased disability days and social role impairments as well as marked reduction in quality of life.

The European findings on the epidemiology of panic disorder are by and large consistent with findings in North America (Eaton et al., 1994), South America, and other countries (Weissman et al., 1997). In line with the international convergence of findings (Horwath et al., 2002), this suggests that PD is cross-culturally much more robust than many other mental disorders. Nevertheless, the extrapolation of data from a few European countries to other nations, and to Europe as a whole, requires caution and careful examination. It must be noted that almost no data are available about the prevalence of PD among various ethnic groups or from the new EU membership states. Noteworthy exceptions include data from Hungary and the Czech Republic. It should also be highlighted that the epidemiology of agoraphobia has received less research attention than PD.

Considerable agreement also exists across studies with regard to high degree of comorbidity associated with PD. PD is commonly associated with agoraphobia, as well as a wide range of disorders including somatoform, affective, and substance use disorders. Mechanisms underlying these high rates of comorbidity are not well understood. Longitudinal studies have provided some support for the „symptom progression model“ that hypothesizes that panic is a temporally primary condition, leading ultimately to depression and subsequently to selfmedication, resulting in substance use disorders (Klein, 1987; Wittchen, 1988; Wittchen et al., 1998c). Cross-sectional studies, however, have also shown that panic disorder may occur as temporally primary to major depression (Roy-Byrne et al., 2000), as well as a secondary condition, or that onsets may even occur simultaneously. Since this issue is of great importance for designing preventive measures, further studies are needed to clarify to what degree panic is a risk factor for depression and substance abuse.

Despite the consistency in the basic descriptive epidemiological data, several questions remain unanswered. These include:

(1) Beyond crude sociodemographic correlates, the vulnerability and risk factors constellations for the onset and further progression of panic disorder and agoraphobia have not been well-studied and remain poorly understood. Such data are of core importance from a public health and prevention perspective. A large number of studies has identified several genetic, environmental, psychological and clinical risk factors for PD in clinical samples; replication studies in community settings, however, are needed. 
(2) Incidence studies that investigate factors associated with onset of panic disorder and agoraphobia in different age cohorts are needed. In addition, there is a need for more information on the onset of secondary comorbid conditions (e.g., secondary depression or substance abuse), among those with PD.

(3) Although clinical wisdom suggests that panic disorder is associated with high utilization of health care resources, only anecdotal findings are available for EU countries. Except for the WHO collaborative study in primary care (Üstün and Sartorius, 1995) conducted in the 80s, the prevalence of these conditions in primary care and specialists settings has not been examined. For example, little is known about how frequently PD patients are recognized and treated in primary care or specialists settings, or how many receive appropriate drug and/or non-drug interventions. Limited evidence from one study suggests that recognition and treatment rates of PD are better than those of other mental disorders. Such findings need replications from countries with different health care characteristics.

(4) Moreover, data about unmet treatment needs in the European countries with weaker economies are of high priority. These issues deserve special attention since several treatment options for PD have been shown to be effective and, perhaps even more importantly, costeffective. In fact, while adequate psychiatric treatment for PD may increase the direct costs of the disorder, they can reduce the total costs when indirect costs (such as work day loss) are taken into account (Salvador-Carulla et al., 1995).

In conclusion, while there have been remarkable advances in epidemiologic research in PD over the past several decades, important questions remain in at least three general areas.

First, there is a need for increased EU-wide coordination regarding diagnostic assessment instruments. Specifically, the establishment of a reliable assessment instrument for future European community studies could be used to create a cumulative epidemiological database of information on PD in the community. Such a resource could aid in minimizing the degree to which differences in current diagnostic methods contribute to inconsistencies in study results. Greater attention on obtaining a broader understanding of risk factors for PD onset, as well as associated outcomes including help-seeking, utilization behaviour, and disability assessment is needed.

Second, there is a need for major incidence studies. These studies should examine both the onset of PD, as well as progression and development of comorbidity and disability. These investigations should include an investigation of the relationship between PD and the full spectrum of mood, anxiety, somatoform and substance use disorders.

Third, there is a need for smaller prevalence studies in the new EU-membership states. Such data would help to confirm and extend the data presented here towards determining the level of unmet needs for intervention for various types of health care provider models, existing in the EU. A systematic assessment in European community residents could provide an empirical background for improved and coordinated health care policy. 
Table 1

Prevalence rates of panic disorder and agoraphobia in Europe (12 month)

\begin{tabular}{|c|c|c|c|c|c|c|c|c|}
\hline \multirow[t]{2}{*}{ Reference } & \multirow[t]{2}{*}{ Site } & \multirow{2}{*}{$\begin{array}{l}\text { Assessment } \\
\text { instrument }\end{array}$} & \multicolumn{3}{|c|}{ Panic disorder } & \multicolumn{3}{|c|}{ Agoraphobia (without panic) } \\
\hline & & & $\begin{array}{l}\text { Total } \\
(\%)\end{array}$ & $\begin{array}{l}\text { Male } \\
(\%)\end{array}$ & $\begin{array}{l}\text { Female } \\
(\%)\end{array}$ & $\begin{array}{l}\text { Total } \\
(\%)\end{array}$ & $\begin{array}{l}\text { Male } \\
(\%)\end{array}$ & $\begin{array}{l}\text { Female } \\
(\%)\end{array}$ \\
\hline unsuthored & Caech Repabbic & $C I D I$ & 0.3 & $a 0$ & 0.5 & 0.7 & a3 & 1.1 \\
\hline Pirkola et al. $(2005)^{b}$ & Finkand & M-CIDI & 1.9 & 1.4 & 2.4 & 1.3 & 1.2 & 1.4 \\
\hline Volbath et al. (1990\% & Zwich, Switzerland & $\begin{array}{l}\text { SPIKE } \\
\text { CIS--R }\end{array}$ & \multicolumn{2}{|c|}{$0.5-0.9$} & & & & \\
\hline Jenkins et al. $(1997)^{d}$ & Great Britain (UK) & SCAN & 1.0 & 0.9 & 1.0 & & & \\
\hline Wittchen et al. (1998a) & Germany, Murich region & M-CIDI & 1.2 & 0.4 & 2.0 & 1.6 & 0.6 & 2.6 \\
\hline Becker ef al $(2000)^{a}$ & Germany Dresden & DIPS & & & 0.8 & & & 1.8 \\
\hline Sradoczky et al. $(2000)$ & Hungary & DIS & 3.1 & 1.5 & 4.3 & & & \\
\hline Stefansson et al. (1994) & Icelend & $\begin{array}{l}\text { DIS } \\
\text { MINI }\end{array}$ & 1.1 & 0.7 & 1.4 & & & \\
\hline Faravelli et al. (2004) & Italy, Florence region & $\begin{array}{l}\text { FPI } \\
\text { CIDI }\end{array}$ & 1.4 & 0.7 & 1.9 & 0.1 & 0.2 & 0.1 \\
\hline Bijl et al. (1998) & The Netherlands & (DSM-R-III) & 2.2 & 1.1 & 3.4 & 1.6 & 0.9 & 2.2 \\
\hline Kringlen et al. (2001) & Oslo, Norway & CIDI 1.1 & 2.6 & 1.5 & 3.4 & 3.1 & 1.3 & 4.5 \\
\hline \multirow[t]{2}{*}{ MoConnell et al. (2002) } & Derry, Northem & SCAN & & & & & & \\
\hline & lre band (UK) & GHQ-28 & 2.4 & & & 0.7 & & \\
\hline Jacohi et al. (2004) & Germany & M-CIDI & 23 & 1.7 & 3.0 & 2.0 & 1.0 & 3.1 \\
\hline ESEMED/MHEDEA & Belgium, France, Germany, & WMH-CIDI & 0.8 & 0.6 & 1.0 & 0.4 & 0.2 & 0.6 \\
\hline \multirow[t]{3}{*}{$\begin{array}{l}2000 \text { investigators, } \\
(2004 a)\end{array}$} & $\begin{array}{l}\text { Italy, The Netherlands, Spain } \\
\text { France }\end{array}$ & WMH-CIDI & 1.6 & 1.5 & 1.8 & 0.7 & 0.5 & 0.8 \\
\hline & Italy (De Girolamo et al., in press) & WMH-CIDI & 1.7 & 0.8 & 2.5 & 1.1 & 0.4 & 1.7 \\
\hline & Spain ${ }^{\circ}$ & WMH-CIDI & 0.7 & 0.4 & 1.0 & 0.3 & 0.1 & 0.4 \\
\hline
\end{tabular}

Studies in small typeritalics are difficult to interpret, e ither because no information has been obxained about methods and analyses or because findings neported are not directly comparable because of the time frame.

" Preliminary data from a national CIDI study provided by Dr. Dragomirecka.

brom Heal th 2000 study provided by Dr. lsometsa and Dr. Lönnikvist, note: age range $>30$.

c 12-Month prevalence of DSM-III panic disorder in a cohort bom 1958 at three waves.

${ }^{4}$ Note: 1-week prevalence (because 12 -month prevalence not available).

- Women age 18-24; note: 1-week prevalence (because 12-month prevelence not aveilable).

${ }^{f}$ Preliminary national ESEMeD data provided by Dr. Alonso (Spain) and Dr. Lépine (France), age range is larger and includes subjects 65 and older.
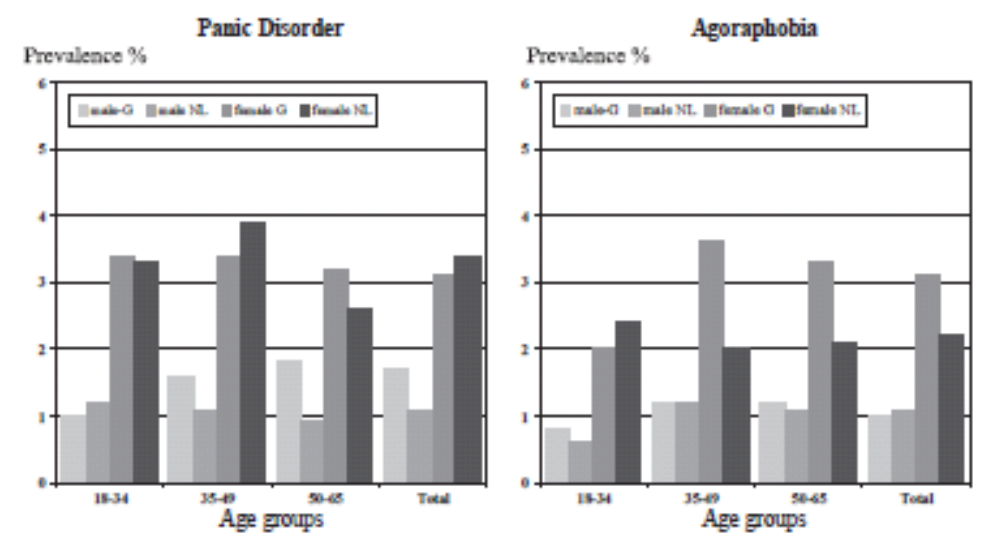

Fig. 1. 12-Month prevalence of panic disorder and agoraphobia by age group in two countries (G-Germany; NL-Nethertands).

\section{References}

- American Psychiatric Association, 1994. Diagnostic and Statistical Manual of Mental Disorders, 4th ed. American Psychiatric Association, Washington.

- Aronson, T.A., 1987. Is panic disorder a distinct diagnostic entity? A critical review of the borders of a syndrome. J. of Nerv. Ment. Dis. 175, 584-594.

- Becker, E.S., Turke, V., Neumer, S., Soeder, U., Krause, P., Margraf, J., 2000. Incidence and prevalence rates of mental disorders in a community sample of young women: results of the „Dresden study“. In: Manz, R., Kirch, W. (Eds.), Public Health Research and Practice: Report of the Public Health Research Association Saxony, vol. II. S. Roderer, Regensburg, pp. 259291. 
- $\quad$ Bijl, R.V., Ravelli, A., van Zessen, G., 1998. Prevalence of psychiatric disorder in the general population: results of The Netherlands Mental Health Survey and Incidence Study (NEMESIS). Soc. Psychiatry Psychiatr. Epidemiol. 33, 587-595.

- Bijl, R.V., De Graaf, R., Ravelli, A., Smit, F., Vollebergh, W.A., 2002. Gender and agespecific first incidence of DSM-III-R psychiatric disorders in the general population. Results from The Netherlands Mental Health Survey and Incidence Study (NEMESIS). Soc. Psychiatry Psychiatr. Epidemiol. 37, 372-379.

- Bijl, R.V., de Graaf, R., Hiripi, E., Kessler, R.C., Kohn, R., Offord, D.R., Üstün, T.B., Vicente, B., Vollebergh, W.A.M., Walters, E.E., Wittchen, H.-U., 2003. The prevalence of treated and untreated mental disorders in five countries. Health Aff. 22, 122-133.

- Burke, K.C., Burke, J.D., Rae, D.S., Regier, D.A., 1991. Comparing age at onset of major depression and other psychiatric-disorders by birth cohorts in 5 United-States community populations. Arch. Gen. Psychitry 48, 789-795.

- Coryell, W., 1988. Panic disorder and mortality. Psychiatr. Clin. North Am. 11, 433- 440.

- De Girolamo, G., Mazzi, F., Morosini, P., Polidori, G., Reda, V., Scarpino, V., Serra, G., in press. La salute mentale in Italia: prevalenza dei disturbi mentali, caratteristiche dei disturbi ed uso dei servizi sanitari. Relazione sullo Stato Sanitario del Paese 2002 (RSSP 2002). Roma, Ministero della Salute.

- $\quad$ Eaton, W.W., Kessler, R.C., Wittchen, H.U., Magee, W.J., 1994. Panic and panic disorders in the United States. Am. J. Psychiatry 151, 413-420.

- Faravelli, C., Paionni, A., 2001. Panic disorder: clinical course, morbidity and comorbidity. In: Griez, E.J.L., Faravelli, C., Nutt, D., Zohar, J. (Eds.), Anxiety Disorders. An Introduction to Clinical Management and Research. Wiley, Chichester, pp. 51-79.

- Faravelli, C., Guerrini Degl'Innocenti, B., Giardinelli, L., 1989. Epidemiology of anxiety disorders in Florence. Acta Psychiatr. Scand. 79, 308-312.

- Faravelli, C., Abrardi, L., Bartolozzi, D., Cecchi, C., Cosci, F., D’Adamo, D., LoIacono, B., Ravaldi, C., Scarpato, M.A., Truglia, E., Rossi Prodi, P.M., Rosi, S., 2004. The Sesto Fiorentino Study: point and one year prevalences of psychiatric disorders in an Italian community sample using clinical interviewers. Psychother. Psychosom. 73, 226- 234.

- Fredman, S.J., Hirshfeld-Becker, D.R., Smoller, J.W., Rosenbaum, J.F., 2003. Childhood antecedents of adult anxiety disorders. In: Nutt, D., Ballenger, J. (Eds.), Anxiety Disorders. Blackwell, Oxford, pp. 135-161.

- Goodwin, R.D., Hamilton, S.P., 2001. Panic attack as a marker of core psychopathological processes. Psychopathology 34, 278-288.

- Goodwin, R.D., Jacobi, F., Thefeld, W., 2003. Mental disorders and asthma in the community. Arch. Gen. Psychiatry, 1125-1130.

- Goodwin, R.D., Lieb, R., Höfler, M., Pfister, H., Bittner, A., Beesdo, K., Wittchen, H.-U., 2004. Panic attack as a risk factor for severe psychopathology. Am. J. Psychiatry 161, 22072214.

- Grasbeck, A., Hagnell, O., Otterbeck, L., Rorsman, B., 1993. Anxiety in the Lundby Study: re-evaluation according to DSM-III-R, incidence and risk. Neuropsychobiology 27, 1-8.

- Horwath, E., Cohen, R.S., Weissman, M.M., 2002. Epidemiology of depressive and anxiety disorders. In: Tsuang, M.T., Tohen, M. (Eds.), Textbook in Psychiatric Epidemiology, 2nd edR Wiley-Liss, New York.

- Isensee, B., Wittchen, H.-U., Stein, M., Höfler, B., Lieb, M., 2003. Smoking increases the risk of panic. Findings from a prospective community study. Arch. Gen. Psychiatry 60, 692-700.

- Jacob, R.G., Furman, J.M., Durrant, J.D., Turner, S.M., 1996. Panic, agoraphobia, and vestibular dysfunction. Am. J. Psychiatry 153,503-512.

- Jacobi, F., Wittchen, H.U., Holting, C., Hofler, M., Pfister, H., Muller, N., Lieb, R., 2004. Prevalence, co-morbidity and correlates of mental disorders in the general population: results from the German Health Interview and Examination Survey (GHS). Psychol. Med. 34, 597611.

- Jenkins, R., Lewis, G., Bebbington, P., Brugha, T., Farrell, M., Gill, B., Meltzer, H., Petticrew, M., 1997. The national psychiatric morbidity surveys of Great Britain—initial findings from the household survey. Psychol. Med. 27, 775-789. 
- Johnson, J., Weissman, M.M., Klerman, G.L., 1990. Panic disorder, comorbidity, and suicide attempts. Arch. Gen. Psychiatry 47, 805-808.

- Kaplan, D.S., Masand, P.S., Gupta, S., 1996. The relationship of irritable bowel syndrome (IBS) and panic disorder. Ann. Clin. Psychiatry 8, 81-88.

- Katerndahl, D.A., Realini, J.P., 1997. Quality of life and panic-related work disability in subjects with infrequent panic and panic disorder. J. Clin. Psychiatry 58, 153- 158.

- Katschnig, H., Amering, M., 1998. The long-term course of panic disorder and its predictors. J. Clin. Psychopharmacol. 18 (Suppl. 2), 6-11.

- Klein, D.F., 1987. Anxiety reconceptualized. In: Klein, D.F. (Ed.), Anxiety. Karger, Basel.

- Klerman, G.L., Weissman, M.M., Oulette, R., Johnson, J., Greenwald, S., 1991. Panic attacks in the community—social morbidity and health-care utilization. JAMA 265 (Suppl. 6), 742746.

- Knäuper, B., Wittchen, H.U., 1994. Diagnosing major depression in the elderly: evidence for response bias in standardized diagnostic interviews? J. Psychiatr. Res. 28 (Suppl. 2), 147-164.

- Kohn, R., Dohrenwend, B.P., Mirotznik, J., 1998. Epidemiological findings on selected psychiatric disorders in the general population. In: Dohrenwend, B.P. (Ed.), Adversity, Stress, and Psychopathology. Cambridge University, Cambridge, pp. 235-284.

- Kringlen, E., Torgersen, S., Cramer, V., 2001. A Norwegian psychiatric epidemiological study. Am. J. Psychiatry 158, 1091-1098.

- $\quad$ Lelliott, P., Marks, I., McNamee, G., Tobena, A., 1989. Onset of panic disorder with agoraphobia. Toward an integrated model. Arch. Gen. Psychiatry 46, 1000-1004.

- Lepine, J.P., Chignon, J.M., Teherani, M., 1993. Suicide attempts in patients with panic disorder. Arch. Gen. Psychiatry 50, 144-149.

- Mansour, V.M., Wilkinson, D.J., Jennings, G.L., Schwarz, R.G., Thompson, J.M., Esler, M.D., 1998. Panic disorder: coronary spasm as a basis for cardiac risk? Med. J. Aust. 168, 390-392.

- Marazziti, D., Toni, C., Pedri, S., Bonuccelli, U., Pavese, N., Lucetti, C., Nuti, A., Muratorio, A., Cassano, G.B., 1999. Prevalence of headache syndromes in panic disorder. Int. Clin. Psychopharmacol. 14, 247-251.

- $\quad$ Marks, I.M., 1987. Fears, Phobias and Rituals. Oxford University Press, New York.

- McConnell, P., Bebbington, P., McClelland, R., Gillespie, K., Houghton, S., 2002. Prevalence of psychiatric disorder and the need for psychiatric care in Northern Ireland. Population study in the District of Derry. Br. J. Psychiatry 181, 214-219.

- Meltzer, H., Gill, B., Petticrew, M., Hinds, K., 1995. OPCS Surveys of Psychiatric Morbidity in Great Britain, Report 1: The Prevalence of Psychiatric Morbidity among Adults Living in Private Households. HMSO, London.

- Merikangas, K.R., Angst, J., Eaton, W., Canino, G., Rubio-Stipec, M., Wacker, H., Wittchen, H.U., Andrade, L., Essau, C., Whitaker, A., Kraemer, H., Robins, L.N., Kupfer, D.J., 1996. Comorbidity and boundaries of affective disorders with anxiety disorders and substance misuse: results of an international task force. Br. J. Psychiatry 30, 58-67.

- Pirkola, S., Isometsä, E., Suvisaari, J., Aro, H., Joukamaa, M., Poikolainen, K., Koskinen, S., Aromaa, A., Lönnqvist, J., 2005. DSM-IV mood-, anxiety and alcohol use disorders and their comorbidity in the Finnish general population. Results from the Health 2000 Study. Soc. Psychiatry Psychiatr. Epidemiol. 40, 1-10.

- Pollack, M.H., Kradin, R., Otto, M.W., Worthington, J., Gould, R., Sabatino, S.A., Rosenbaum, J.F., 1996. Prevalence of panic in patients referred for pulmonary function testing at a major medical center. Am. J. Psychiatry 153, 110-113.

- $\quad$ Reed, V., Wittchen, H.U., 1998. DSM-IV panic attacks and panic disorder in a community sample of adolescents and young adults: how specific are panic attacks? J. Psychiatr. Res. 32, 335-345.

- $\quad$ Roy-Byrne, P.P., Stang, P., Wittchen, H.U., Ustun, B., Walters, E.E., Kessler, R.C., 2000. Lifetime panic-depression comorbidity in the National Comorbidity Survey-association with symptoms, impairment, course and help-seeking. Br. J. Psychiatry 176, 229-235.

- Salvador-Carulla, L., Segui, J., Fernandez-Cano, P., Canet, J., 1995. Costs and offset effect in panic disorders. Br. J. Psychiatry (Suppl. 27),23-28. 
- Stefansson, J.G., Lindal, E., Bjornsson, J.K., Gudmundsdottir, A., 1994. Period prevalence rates of specific mental disorders in an Icelandic cohort. Soc. Psychiatry Psychiatr. Epidemiol. 29, 119-125.

- Szadoczky, E., Papp, Z., Vitrai, J., Füredi, J., 2000. A hangulat- es szorongasos zavarok elöfordulasa a felnott magyar lakossag köreben. Orv. Hetil. 141 (Suppl. 1), 17-22.

- The ESEMeD/MHEDEA 2000 investigators, 2004a. Prevalence of mental disorders in Europe: results from the European Study of the Epidemiology of Mental Disorders (ESEMeD) project. Acta Psychiatr. Scand., Suppl. 420, 21-27.

- The ESEMeD/MHEDEA 2000 investigators, 2004b. 12-Month comorbidity patterns and associated factors in Europe: results from the European Study of the Epidemiology of Mental Disorders (ESEMeD) project. Acta Psychiatr. Scand., Suppl. 420, 28-37.

- The ESEMeD/MHEDEA 2000 investigators, 2004c. Disability and quality of life impact of mental disorders in Europe: results from the European Study of the Epidemiology of Mental Disorders (ESEMeD) project. Acta Psychiatr. Scand., Suppl. 420, 38-46.

- Vollrath, M., Koch, R., Angst, J., 1990. The Zurich Study: IX. Panic disorder and sporadic panic: symptoms, diagnosis, prevalence, and overlap with depression. Eur. Arch. Psychiatr. Neurol. Sci. 239, 221-230.

- Von Korff, M.R., Eaton, W.W., Keyl, P.M., 1985. The epidemiology of panic attacks and panic disorder. Am. J. Epidemiol. 122, 970-981.

- Üstün, T.B., Sartorius, N., 1995. Mental Illness in General Health Care: An International Study. World Health Organization, Chichester, Wiley.

- Weiller, E., Bisserbe, J.C., Maier, W., Lecrubier, Y., 1998. Prevalence and recognition of anxiety syndromes in five European primary care settings. A report from the WHO study on psychological problems in general health care. Br. J. Psychiatry 34, 18-23.

- Weissman, M.M., Klerman, G.L., Markowitz, J.S., Ouellette, R., 1989. Suicidal ideation and suicide attempts in panic disorder and attacks. N. Engl. J. Med. 321, 1209-1214.

- $\quad$ Weissman, M.M., Markowitz, J.S., Ouellette, R., Greenwald, S., Kahn, J.P., 1990. Panic disorder and cardiovascular/cerebrovascular problems: results from a community survey. Am. J. Psychiatry 147, 1504-1508.

- Weissman, M.M., Bland, R.C., Canino, G., Faravelli, C., Greenwald, S., Hwu, H.G., Joyce, P.R., Karam, E.G., Lee, C.K., Lellouch, J., Lepine, J.P., Newman, S.C., OakleyBrowne, M.A., Rubio-Stipec, M., Wells, J.E., Wickramaratne, P.J., Wittchen, H.U., Yeh, E.K., 1997. The cross national epidemiology of panic disorder. Arch. Gen. Psychiatry 54, 305-309.

- Wittchen, H.U., 1988. Natural course and spontaneous remissions of untreated anxiety disorders - results of the Munich follow-up study (MFS). In: Hand, I., Wittchen, H.U. (Eds.), Panic and Phobias: 2. Treatments and Variables Affecting Course and Outcome. Springer, Berlin, pp. 3-17.

- Wittchen, H.-U., 1994. Reliability and validity studies of the WHO-Composite International Diagnostic Interview (CIDI): a critical review. J. Psychiatr. Res. 28, 57-84.

- Wittchen, H.-U., 2000. Met and unmet need for interventions in community cases with anxiety disorders. In: Andrews, G., Henderson, S. (Eds.), Unmet Need in Psychiatry. Problems, Resources, Responses. Cambridge University Press, Cambridge, pp. 256-276.

- Wittchen, H.-U., Jacobi, F., 2005. Size and burden of mental disorders in Europe-a critical review and appraisal of 27 studies. Eur. Neuropsychopharmacol 15, 357-376.

- Wittchen, H.U., Müller, N., Storz, S., 1998a. Psychische Störungen: Häufigkeit, psychosoziale Beeinträchtigungen und Zusammenhänge mit körperlichen Erkrankungen. Gesundheitswesen 60, 85-100.

- Wittchen, H.U., Nelson, C.B., Lachner, G., 1998b. Prevalence of mental disorders and psychosocial impairments in adolescents and young adults. Psychol. Med. 28, 109-126.

- Wittchen, H.U., Reed, V., Kessler, R.C., 1998c. The relationship of agoraphobia and panic in a community sample of adolescents and young adults. Arch. Gen. Psychiatry 55, 1017-1024.

- Wittchen, H.-U., Lachner, G., Wunderlich, U., Pfister, H., 1998d. Test-retest reliability of the computerized DSM-IV version of the Munich-Composite International Diagnostic Interview (M-CIDI). Soc. Psychiatry Psychiatr. Epidemiol. 33, 568-578. 
- Wittchen, H.-U., Pfister, H., Schmidtkunz, B., Winter, S., Müller, N., 2000. German national health interview and examination survey—mental health supplement (GHS-MHS): Part 2.

Tables and instructions for public use file (supplement to final report BMBFBW $01 \mathrm{EH}$ 9701/8). Munich: Max-Planck-Institute for Psychiatry, Clinical Psychology and Epidemiology.

- World Health Organization, 1993. The ICD-10 classification of mental and behavioural disorders. Diagnostic Criteria for ResearchWorld Health Organization, Geneva.

- Wunderlich, U., Bronisch, T., Wittchen, H.-U., 1998. Comorbidity patterns in adolescents and young adults with suicide attempts. Eur. Arch. Psychiatry Clin. Neurosci. 248, 87-95.

- Zaubler, T.S., Katon, W., 2003. Panic disorder and medical llness. In: Nutt, D., Ballenger, J. (Eds.), Anxiety Disorders. Blackwell, Oxford, pp. 297-311. 